\title{
NUESTROS MUERTOS, VUESTRA GUERRA: O DISCURSO E O SILENCIAMENTO DO DIZER NOS ATENTADOS TERRORISTAS DA ESPANHA EM 2004*
}

\author{
Fabio Scorsolini-Comin; \\ Leda Verdiani Tfouni; \\ Angelita Zamberlan Nedel, \\ da Universidade Federal do Triângulo Mineiro (UFTM).
}

\begin{abstract}
Resumo: Com base na análise do discurso de matriz francesa (AD), este artigo tem por objetivo investigar os discursos populares acerca dos atentados terroristas, ocorridos em Madrid, Espanha, no ano de 2004. A análise do enunciado "Nuestros muertos, vuestra guerra" (Nossos mortos, vossa guerra), escrita em algumas faixas em manifestações da época, revelou que não há um sentido único para a mesma, destacando-se a necessidade de olharmos para o contexto de enunciação e para a história de produção dos sentidos que não remetem apenas aos atentados de 2004, mas a outros eventos históricos do país (separatismo e grupos de conflito) e também do contexto mundial, como os atentados da Al Qaeda aos EUA em 2001.
\end{abstract}

Palavras-chave: Análise do discurso. Silenciamento. Interdiscurso. Terrorismo. Espanha.

Not a grave of the murdered for freedom but grows seed for freedom... in its turn to bear seed, which the winds carry afar and re-sow, and the rains and snows nourish. Not a disembodied spirit can the weapons of tyrants let loose, but it stalks invisibly over the earth... whispering counseling cautioning. Liberty let others despair of you... I never despair of you. (WHITMAN, 1855-2008)

Um minuto de silêncio foi o que pediu uma jornalista da televisão da capital espanhola ao ler um manifesto para a população que foi às ruas em um protesto contra o terrorismo. Foi em silêncio que quase cinquenta

\footnotetext{
* Artigo recebido em 27/10/2011 e aprovado em 22/5/2012.
} 
mil pessoas do município de Alcalá de Henares, de onde partiram os trens atacados no dia 11 de março de 2004, manifestaram dor e revolta diante do atentado na cidade de Madrid.

Os manifestantes, em silêncio quase absoluto, fizeram o percurso pela cidade natal de Cervantes, onde cerca de vinte e seis habitantes morreram nas explosões. Segundo o France Presse, no meio da praça havia um entrelaçado de fitas pretas deixado pelos moradores da cidade, com frases como: "As bombas do Iraque explodem em Madrid"; "Ódio eterno aos culpados"; "Este trem sempre estará dentro de mim". A mesma jornalista madrilenha pedia, após o silêncio, uma salva de palmas para simbolizar a força com que deveriam combater o terrorismo.

Mas o que esconderia esse silêncio? O que há por trás? Uma escuta, uma ressonância, uma interrogação, uma denúncia? Só na morte existe o silêncio? Far-se-ia um minuto de silêncio para remeter a um silêncio que só existiria na morte? Ou o silêncio seria por respeito, por um calar, pela memória de outrem, por um protesto? Sim, o silêncio pode ser um protesto, mas no silêncio só ouvimos o silêncio? O minuto de silêncio seria um lugar da memória? Para o historiador francês Pierre Nora (1984), pode-se afirmar que sim. Ainda para Nora, os lugares de memória possuem três acepções ou formas: (a) lugares materiais onde a memória social se ancora e pode ser apreendida pelos sentidos; (b) lugares funcionais que alicerçam memórias coletivas; e (c) lugares simbólicos nos quais a memória coletiva pode se expressar e se revelar. Assim, há que se considerar que esses lugares de memória são construções históricas que revelam processos sociais, conflitos e paixões.

A partir dessa contribuição de Pierre Nora (1984), pode-se afirmar que o silêncio feito para lembrar os mortos também atua como uma forma de protesto; um protesto sem gritos, mas não mudo. Esse protesto em forma de silêncio atua como um registro da memória que se enraíza no concreto (protesto), no espaço (praças e espaços públicos), no gesto (manifestação), na imagem (cartazes com frases e slogans relacionados aos atentados terroristas) e no objeto. Assim, temos evidências de que, como postula Orlandi (1995), o silêncio também significa. Pode ser mais cortante que um grito; ele traz em si não apenas a lembrança de quem se foi, mas sintetiza o pensamento, guarda/incorpora o não dito. $O$ dito e o não dito coabitam em um jogo de forças que se atualizam no discurso, nos gestos e nas ações do falante. $O$ silêncio pode parecer uma não ação, todavia é uma ação. Parece ausência, parece prece, parece vácuo, parece buraco negro, mas pulsa - sanguíneo, latejante, penetrante; uma interrogação. 
O silêncio também denuncia. Em Dom Casmurro, Machado de Assis (2000) escreve que "Capitu encobria com palavras o que Bentinho denunciava no silêncio". O silêncio de Bentinho denunciava o quê? Denunciava seu amor por Capitu. E o silêncio na manifestação na Espanha, que levou cinquenta mil pessoas às ruas, denunciava o quê? Desespero, terror, dor, medo? Aqui se aplicaria o ditado Quem cala, consente? Seria verdadeiro se não tivesse sido feito algo; porém algo foi feito. $O$ silêncio não se coloca como algo transparente, mas como possuidor de uma espessura, colocando processos significativos complexos (ORLANDI, 1995).

Os espanhóis saíram às ruas, gritaram (ou silenciaram), levantaram bandeiras e faixas, expuseram seu luto ao mundo de maneira não velada, de modo oposto ao que aconteceu após o 11 de setembro de 2001, nos Estados Unidos. Estariam os norte-americanos com medo, ou simplesmente consentindo com algo não dito?

Amparados nessas questões é que apresentamos este artigo que tem por objetivo investigar uma manifestação particular dos discursos populares acerca dos atentados terroristas de 2004, na Espanha, por meio da análise do discurso pêcheutiana.

\section{EXPLORANDO SENTIDOS NO DISCURSO}

Every existence has its idiom... every thing has an idiom and tongue; He resolves all tongues into his own, and bestows it upon men... and any man translates... and any man translates himself also: One part does not counteract another part... He is the joiner... he sees how they join. (WHITMAN, 1855)

"Nuestros muertos, vuestra guerra". Esse foi o enunciado-slogan' escrito em algumas faixas em protestos e manifestações acerca dos atentados terroristas ocorridos em Madrid, em 11 de março de 2004.

Para analisarmos essa ocorrência, temos que elucidar os contextos em que ela foi dita/escrita e suas condições de produção. Ao ponderar as condições de produção do anúncio, deve-se, de início, considerar que junto com o contexto de enunciação existe um contexto social mais amplo, no qual o sujeito do discurso é historicamente determinado. Isso destrói a crença de um sentido único e admite a existência de efeitos de sentido. Esses efeitos estão imersos "numa relação de forças estabelecidas pelos lugares sociais ocupados pelos interlocutores" (TFOUNI, 1988).

A Análise do Discurso de tradição pêcheutiana (AD) é uma disciplina indiciária, aproximando-se de uma concepção de sujeito essencialmente dividido. A análise do discurso nasce na França, na década de sessenta, 
marcada pelo movimento estruturalista, pelas mãos de Michel Pêcheux. A AD, segundo Pêcheux e Fuchs (1993), articula-se na confluência de três regiões do conhecimento: o materialismo histórico (teoria das formações sociais e suas transformações e, também, a teoria das ideologias); a linguística (teoria dos mecanismos sintáticos e dos processos de enunciação); e a teoria do discurso (teoria da determinação histórica dos processos semânticos). Essas três regiões do conhecimento (acrescentam os autores) seriam atravessadas e articuladas por uma teoria da subjetividade de natureza psicanalítica. No Brasil, muito do que foi produzido pelos analistas do discurso franceses em sua gênese foi retomado e/ou ampliado, em termos teóricos, por Orlandi, sendo que a maior contribuição original dessa autora para o objetivo de análise do presente trabalho foi o livro sobre o silêncio (ORLANDI, 1995), texto extensamente comentado aqui.

Para a $A D$, a condição da linguagem e do próprio sujeito é a incompletude; em outras palavras, sujeitos e sentidos não estão completos, prontos, acabados e constituídos definitivamente, mas se constituem e funcionam sob o modo do entremeio, da relação, da falta, do movimento; a incompletude atesta a própria abertura do simbólico (GADET \& PÊCHEUX, 2004). É essa incompletude que abre espaço para a significação, para a constituição do sujeito e a interpretação. Pêcheux (2004) focaliza o discurso como efeito de sentidos entre interlocutores, considerando a não transparência da linguagem. Seguindo Pêcheux, Orlandi aponta que "[...] a noção de sujeito em AD carrega consigo a de contradição e da incompletude" (ORLANDI, 2001, p. 12). A linguagem e a significação encontram-se abertas e incompletas, fazendo com que os sentidos não estejam fechados, mas em movimento, circulando no espaço discursivo. Portanto, o sentido está sempre em curso e não há como apontar um começo definido ou um fim. Os dizeres estão sempre produzindo efeitos.

Um conceito bastante explorado pela $A D$ é o de interdiscurso, que corresponde à relação do discurso com uma multiplicidade de discursos. Só uma parte do dizível é acessível ao sujeito. Esse sujeito, na visão de Pêcheux, é interpelado pela ideologia, impedindo que o mesmo reconheça as determinações que o colocaram no lugar que ele ocupa. O sujeito é conduzido e, tendo a impressão de estar agindo por sua própria vontade, ocupa um determinado lugar na luta de classes, no conflito entre a classe dominante e a classe dominada.

É esse conflito que determinará as formações ideológicas (conjunto complexo de atitudes e de representações que não são individuais nem universais). Essas formações ideológicas comportam uma ou várias formações 
discursivas interligadas que determinam o que pode e o que deve ser dito, a partir de uma posição dada em uma conjuntura sócio-histórica (PÊCHEUX, 1969).

Toda formação discursiva deriva de determinadas condições de produção que são, ao mesmo tempo, enunciativas e sócio-históricas, em que há de se considerar tanto os contextos situacionais quanto a história inscrita na sequência discursiva. É esse importante objeto teórico - colocado por Pêcheux como essencial à análise - que vai ser explicitado na primeira parte do artigo. Acrescentamos que, em AD, não é possível pensar a língua e o discurso separados das condições de produção; caso contrário, teríamos uma análise exegética ou conteudística, em que somente o dito ou o escrito serviriam de base, sem qualquer referência ao modo como a história se inscreve ali, produzindo efeitos. Por outro lado, as condições de produção são responsáveis pelas formações imaginárias, que se referem à posição dos sujeitos no discurso e surgem a partir da relação de forças, da relação de sentidos e da antecipação (que leva o sujeito a antecipar o lugar e o efeito que seu discurso terá sobre o outro).

Um pouco dessas condições de produção será explicitado no decorrer deste trabalho, assim como a questão da alteridade. Para Bakhtin - um teórico que influenciou bastante a constituição da AD enquanto ciência -, a questão das palavras alheias e das palavras próprias (assim como a conversão das duas em palavras próprias/alheias) constitui-se em um mecanismo que ilustra a origem heterogênea e polissêmica da constituição do discurso: uma multidão de vozes, das quais, em determinado momento histórico, uma predomina sobre as outras, mas nunca as apaga. Assim escreve Bakhtin:

Como produto humano, a linguagem guarda a história das relações sociais, traz a lembrança das oposições de classe, constitui o meio no qual se produzem lentas acumulações quantitativas de mudanças, e por isso é capaz de registrar as fases transitórias mais íntimas, mais efêmeras das mudanças sociais. (BAKHTIN, 1999, p. 41)

Vamos, pois, passar à análise.

\section{O DISCURSO NO ATENTADO TERRORISTA DE MADRID}

No caso do enunciado veiculado na manifestação em Madrid ("Nuestros muertos, vuestra guerra"), como pode ser observado na Figura 1, o discurso não é apenas de um determinado falante e não se encerra em si mesmo, mas remete a outros discursos, de outros falantes, de outras 
sociedades, atualizando uma memória dos sentidos (do interdiscurso) e fazendo significar algo novo na contemporaneidade.

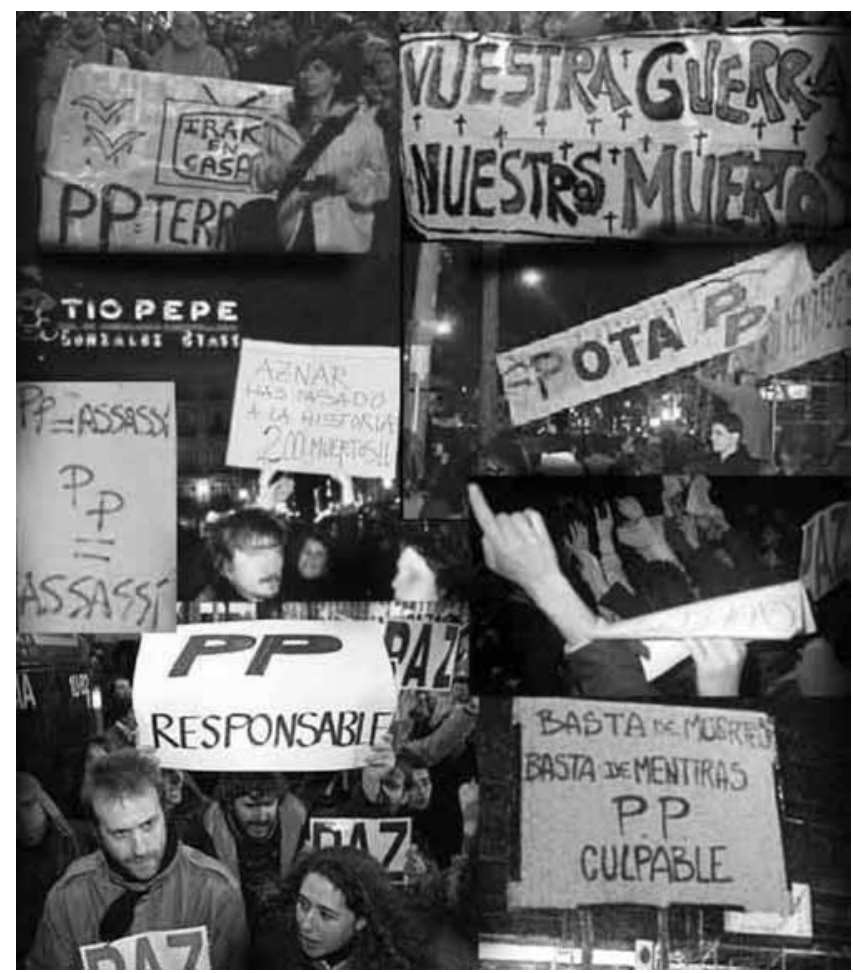

Figura 1: Protestos realizados na cidade de Madrid, em março de 2004, por conta dos atentados terroristas. Na parte superior direita, podemos observar a frase alvo de nossa análise. Recuperado de: <http://img111.imageshack.us/img111/2567/asesinos2tn0.jpg>, em 27 abr. 2010.

Embora o discurso esteja sendo produzido na Espanha, um país europeu com determinadas heranças históricas e culturais, ele não diz respeito apenas a esse contexto pura e simplesmente. Ele carrega outros tantos discursos que se interpenetram e se cravam nos falantes, nas suas falas, nas suas ações, em seus movimentos. Há uma multiplicidade de sentidos implícitos e explícitos que atuam em um jogo de forças e que se expressam não apenas no discurso que se coloca, mas em todas as condições e desdobramentos do mesmo. Todo discurso remete a outro(s) discurso(s), visto que existe uma história da produção de sentidos (o já-dito; o plano dos enunciados) que se integra à enunciação. Desse modo, temos sempre 
duas forças antagônicas operando na produção discursiva: a repetição do já-dito, por um lado, e, por outro, algo de novo que emerge em diferentes circunstâncias de enunciação.

Na primeira vez que nos deparamos com a frase "Nuestros muertos, vuestra guerra", seríamos levados, inconscientemente, a pensar que ela contivesse um sentido único, que nela se encerraria tudo o que precisasse ser dito. Essa ilusão de completude do dizer e do sentido origina-se no esquecimento número 1, descrito por Pêcheux (1969), segundo o qual o falante acredita ser a origem do dizer; ou seja, os sentidos seriam criados por ele à medida que enuncia. Tal esquecimento, na sociedade moderna, é reforçado pelo discurso pedagógico escolar que, via de regra, "ensina" ao aluno que há uma resposta "certa" para as questões, fazendo, desse modo, a pasteurização de um sentido único.

No caso do enunciado em análise, esse sentido único seria o de que os mortos pertencem a um grupo/sociedade/país, possivelmente a Espanha (devido ao uso do idioma espanhol), e que essas mortes teriam sido causadas em decorrência de uma guerra pela qual eles não seriam responsáveis. Esse sentido estaria acabado, ou melhor, pareceria estar terminado. Porém, do ponto de vista da $A D$, vemos que a incompletude faz parte do dizer: tudo não se diz. O sujeito se esforça em buscar um sentido unívoco, mas atinge apenas significações circulares e provisórias, já que a linguagem se constitui como lugar de equívoco, e o sentido nunca é completo; ele é sempre provisório e esburacado, podendo vir a sofrer desvios, inversões, deslocamentos sob a influência da história e da memória.

Outra impressão, fruto de uma interpretação linguageira, ${ }_{1}^{2}$ foi a de que a frase possuía um caráter original, novo. É nisso que consiste exatamente o esquecimento número 1 , ou o ocultamento ideológico, por meio do qual o sujeito enunciador tem a ilusão de que ele é a fonte de seu discurso (PÊCHEUX, 1969). Esse esquecimento é de natureza inconsciente e se apresenta como inerente à prática subjetiva ligada à linguagem. A partir disso, coloca-se que os processos discursivos não poderiam ter a sua origem no sujeito, mas que se realizariam nesse mesmo sujeito. $O$ sujeito teria a impressão de ser livre e responsável pelo "seu" discurso; esse se apresentaria para ele como um instrumento límpido do pensamento e um reflexo justo da realidade. Segundo o autor, o sujeito se esquece de que não pode encontrar-se fora da formação discursiva que o domina, e de que existem vários sentidos possíveis, sempre com um dominante.

Do mesmo modo, consideramos o esquecimento número 2 (PÊCHEUX, 1969) que dá ao sujeito a ilusão de realidade do pensamento; ou seja, ele 
acredita que o que ele fala é exatamente igual ao que ele pensa, quando, na realidade, aquilo que não é dito continua a significar nas entrelinhas. No enunciado "Nuestros muertos, vuestra guerra", essa ilusão opera de maneira a desconsiderar outros sentidos possíveis que ficam no não dito, mas significam pela sua ausência. Cria-se o efeito de que aquela era a única maneira possível de dizer. Assim, o esquecimento número 2 é do nível da formulação. Para a $A D$, o discurso não é a linearidade e a expressão do pensamento, mas é, de forma precisa, o efeito de sentidos entre interlocutores determinados historicamente. Haveria aqui um ocultamento de caráter linguístico, diferente do esquecimento número 1, de caráter ideológico. Para ultrapassar esses dois esquecimentos, é preciso que o analista leve em consideração o contexto, ou condições de produção do discurso. Por condições de produção, entendemos as circunstâncias imediatas: o contexto estrito da enunciação e, também, o contexto no sentido lato, ou seja, o processo histórico que desembocou naquele enunciado e possibilitou que ele se tornasse possível.

Para a $A D$, os principais processos de constituição da linguagem são a paráfrase e a polissemia, que implicam um movimento constante de expansão e contenção de sentido. Segundo Orlandi (2001), todo funcionamento da linguagem se assenta na tensão entre processos parafrásticos e processos polissêmicos. A paráfrase são as várias formas de se dizer uma mesma coisa, representando um retorno aos mesmos espaços do dizer, produzindo diferentes formulações do mesmo dizer sedimentado. A polissemia é a própria condição de existência da linguagem, e seu efeito é provocar um deslocamento do mesmo, dando margem a novas significações.

O discurso se faz nessa tensão entre o mesmo e o diferente, fazendo com que os sentidos se movimentem, façam seus percursos e (se) signifiquem. "[...] toda vez que falamos, ao tomar a palavra, produzimos uma mexida na rede de filiação dos sentidos, no entanto, falamos com palavras já ditas" (ORLANDI, 2001, p. 36).

Entre o mesmo e o diferente, segundo ainda Orlandi (2001), o analista do discurso se propõe a compreender como o político e o linguístico se inter-relacionam na constituição do sujeito e na produção dos sentidos ideologicamente assinalados. A linguagem só é possível nesse constante duelo entre a paráfrase e a polissemia, entre o mesmo e o diferente; diferente que remete ao mesmo, em um jogo contínuo e ininterrupto.

Olhando por esse ângulo, temos que o enunciado "Nuestros muertos, vuestra guerra" poderia se encaixar também em outros contextos, de outras guerras, em que sempre pessoas inocentes acabam morrendo em lugar de culpados - guerras inclusive na própria Espanha. Assim, seria natural/normal 
os mortos serem "nossos" e a guerra de outrem. Aqui se vê, ainda, a ideologia naturalizando o sentido.

E se, tentando evidenciar o esquecimento número 2, construíssemos uma paráfrase; por exemplo:"Nuestra guerra, vuestros muertos"? Com certeza, os sentidos atribuídos seriam diferentes, visto que destinatário e enunciador "mudariam de lado", e a responsabilização pelos mortos ficaria a cargo deste último, produzindo o efeito de que o sujeito falante se responsabiliza pela guerra, mas se exime de uma preocupação com os mortos.

Investigando mais de perto as marcas formais, especialmente a sintaxe do enunciado, pode-se notar que há uma vírgula (uma pausa) separando dois sintagmas; percebe-se também a ausência de verbos. Outro elemento que deve ser notado é o uso dos pronomes "nuestros" e "vuestra", palavras dêiticas, cujo sentido varia de acordo com a perspectiva de uso com relação a emissor e receptor. $O$ fato de estarem no plural indica um coletivo. Portanto, o uso da vírgula mais a oposição entre "nuestros" e"vuestra" indicam um antagonismo entre "quem lamenta os mortos" e "quem faz a guerra".

Nota-se, ainda, que a ideologia naturaliza um sentido, pois para existir uma guerra há de existir, no mínimo, duas facções em oposição, a guerra se configurando, assim, como algo compartilhado. A relação entre guerra e mortes é de causa e efeito: a guerra causa mortes. Como uma guerra sempre supõe dois lados antagônicos e em litígio, seria correto inferir que a guerra causaria mortos de ambos os lados. Assim, se a guerra é "vuestra", os "muertos" deveriam ser também "vuestros", o que não é visto na frase - pelo contrário, a guerra é "vuestra" e os "muertos" são "nuestros".

Uma pontuação interessante é a utilização de dois pronomes possessivos ("nuestros" e "vuestra") que geram a relação entre possuidor e coisa possuída. Tanto os mortos quanto a guerra pertencem a alguém, ou seja, o que se apresenta é uma relação de posse. Quem enuncia a frase possui ou sente possuir os mortos; os mortos pertencem a ele, fazem parte dele. A guerra pertence a outro(s), e não àquele grupo identificado pelo sujeito do enunciado, que é indeterminado semanticamente e se identifica com o lugar de "nuestros", marcando uma divisão radical com "vuestra" (guerra).

Ao marcar sintaticamente sua separação entre "aqueles que fazem a guerra" e"os que ficam com os mortos", o sujeito parece se eximir da culpa pela guerra, transferindo essa culpa a outrem. Para quem se fala? Para os próprios espanhóis, para os Estados Unidos, para o Iraque, para a Al Qaeda, para o ETA, para o mundo? Essa responsabilidade poderia estar sendo delegada ao governo espanhol, às políticas neoliberais, aos Estados Unidos, entre outras possibilidades. Mas, antes de continuar, é preciso que se entenda um pouco 
mais acerca das condições de produção do atentado em Madrid, destacandose, de modo especial, o contexto sócio-histórico.

$\mathrm{Na}$ imprensa escrita e mesmo na televisão e na internet, tais atentados ocuparam, e ainda continuam ocupando, uma posição de destaque, dada a sua brutalidade, justamente por ter atingido "pessoas inocentes" (entenda-se, por "inocente", alguém não diretamente responsável pelo atentado).

Após os atentados, o governo espanhol (Partido Popular) atribuiu a culpa pelos mesmos ao grupo terrorista basco ETA (Euskadi Ta Askatasuna ou Pátria Basca e Liberdade) - apesar de a polícia espanhola ter levantado suspeitas e encontrado provas para a chamada"Pista Árabe", ou seja, para a Al Qaeda ou grupos a ela ligados. O Partido Socialista, de oposição ao governo, ao contrário, não culpou o ETA. Segundo Clóvis Rossi, do Jornal Folha de São Paulo (2004), se ficasse comprovado que fora o ETA, o governo sairia favorecido, porque teria vendido a ideia de que os socialistas (seus opositores) são brandos com o grupo terrorista.

A eleição que ocorreu logo após os atentados teve como vencedor o candidato do Partido Socialista, José Luis Rodríguez Zapatero, que até então estava em segundo lugar em todas as pesquisas de intenção de voto (perdendo para o partido do até então atual governo espanhol), evidenciando-se a influência dos atentados e das declarações no voto popular.

É importante ressaltar que, na véspera das eleições, a hipótese mais provável pela responsabilidade dos atentados recaía sobre a Al Qaeda, grupo terrorista chefiado por Osama Bin Laden. Segundo a polícia, um anônimo avisou da existência de um vídeo em que um homem com roupas típicas árabes e sotaque marroquino diz: "Declaramos nossa responsabilidade pelo ocorrido em Madrid. É uma resposta aos crimes no Afeganistão e no Iraque. Se não pararem com as injustiças, haverá mais".

Outro fato que se julga relevante no bojo dessa discussão é a questão de que a Espanha tem um problema não resolvido: suas dezessete regiões autônomas, onde proliferam os ideais separatistas. O Partido Popular - ao contrário do Partido Socialista - se recusava a negociar e aprofundar o processo de autonomia, minando os esforços dos que buscam a independência. Assim, a acusação do Partido Popular ao ETA pelos atentados estaria atendendo aos interesses da classe política conservadora, visto que o ETA constitui um dos grupos separatistas mais atuantes e fortes da Espanha. A comprovação da autoria dos atentados pela Al Qaeda tornou possível a interpretação de que o crime poderia ter sido cometido como represália pelo envolvimento do governo espanhol na Guerra do Iraque (enviando tropas para lá, apesar da oposição majoritária dos espanhóis) e por seu apoio aos Estados Unidos. 
Com esses fatos, fica clara a formação social presente, ou seja, a luta de classes. O governo (Partido Popular), que corresponde a uma minoria, tomou uma decisão que dizia respeito a todos os espanhóis: a de apoiar os Estados Unidos na guerra contra o Iraque, decisão essa fortemente criticada pela população.

Assim, pensar o mecanismo de interpelação do sujeito falante à ordem do discurso implica articular e, ao mesmo tempo, dissociar dois níveis de descrição: (a) o nível da enunciação (o eu, aqui, agora, do discurso); e (b) o nível dos enunciados - ou interdiscurso (pré-construído) - série de formulações que se articulam em formas linguísticas determinadas (citação, repetição, paráfrase, oposição, antítese etc.). É aí, no interdiscurso, que temos o domínio da memória, ou seja, a exterioridade constitutiva dos enunciados, espaço no qual o sujeito falante não tem um lugar já definido, visto que, no domínio da memória, temos uma voz sem dono (COURTINE, 1999).

Dessa forma, ao enunciar, o falante situa-se em algum ponto dessa rede interdiscursiva que constitui a memória do dizer, na qual se localizam os enunciados (o já-formulado). É assim que deve ser compreendida a afirmativa de que, para fazerem sentido, em um ato de enunciação, é preciso que as palavras já façam sentido no território do interdiscurso, ou dos enunciados. Segundo Pêcheux (1969), olhar os fenômenos linguísticos do ponto de vista da enunciação, ou do seu funcionamento, implica aceitar que esse funcionamento é, em parte, não linguístico, e que ele só pode ser definido em relação às suas condições de produção.

Desse modo, a AD propõe-se a interpretar os enunciados de um corpus através da compreensão do processo que os colocou em funcionamento, ou seja, suas condições de produção. E o que constitui as condições de produção de um discurso? O quadro institucional, o aparelho ideológico no qual esse discurso se inscreve, as representações imaginárias que estão subjacentes, a conjuntura política em que ele foi produzido, as relações de forças, os efeitos estratégicos (de persuasão) procurados etc..

Ignorando o fato de que a frase aqui analisada foi escrita em espanhol e produzida em um contexto específico, é importante prestar atenção na possibilidade de migração de sentido do enunciado "Nuestros muertos, vuestra guerra" para outras regiões de significação em que ele poderia assumir outros sentidos, pensando em outros contextos históricos, como o de um iraquiano revoltado em um protesto; de um pacifista, querendo mostrar ao mundo as atrocidades cometidas pelos Estados Unidos em sua terra; ou de um estudante chinês clamando por liberdade na Praça da Paz Celestial. 


\section{CONSIDERAÇÕES FINAIS}

Not a day passes... not a minute or second without an accouchement; Not a day passes... not a minute or second without a corpse. (WHITMAN, 1855)

A linguagem e a história são pontos fundamentais na compreensão das questões humanas e sociais. Por ser polissêmica e dialógica, a palavra traz marcas culturais, sociais e históricas. O contexto histórico transforma a palavra fria do dicionário em fios dialógicos vivos que refletem e refratam a realidade que a produziu (BAKHTIN, 1999).

Por meio da linguagem, as divergências, a materialização da luta de classes, a disputa pelo poder por grupos antagônicos, as crenças religiosas e as demonstrações de preconceitos são materializadas. Dentro desse jogo dialético - da palavra que liga a palavra -, o sujeito falante produz seu discurso sem se livrar do discurso do outro. Essa é a relação entre inter e intradiscurso, que implica alteridade e heterogeneidade.

A consideração de que o contexto, em $A D$, faz parte do sentido permite uma compreensão não apenas mais abrangente, mas também mais profunda do efeito de sentidos entre interlocutores determinados sócio-historicamente. Para a AD, o sentido se apresenta sempre incompleto e retroativo. Isso quer dizer que não há sentidos fechados ou categorizados a priori, mas em movimento, circulando no espaço discursivo.

Os contextos da $A D$ explorados nesta análise são o linguístico, o imediato e o mediato. $O$ primeiro deles diz respeito às regras de uso da linguagem, os dados linguísticos brutos com os quais o analista do discurso trabalha, ou seja, o próprio enunciado. Aqui esse contexto corresponde à frase "Nuestros muertos, vuestra guerra". O contexto de enunciação, ou imediato, corresponde às perguntas como "quem fala", "de onde", "para quem", "como se fala", "em que circunstância" etc.. Por último, o contexto mediato, ou sóciohistórico, se refere à história da produção do sentido.

Podemos dizer, ainda, que o sujeito enunciador do slogan assumiu um determinado posicionamento no discurso, identificando-se com uma formação ideológica que o coloca como antagonista do governo conservador espanhol (fato indiciado pelo "vuestra"). O contexto de enunciação situa a produção do slogan em uma manifestação popular contra o atentado terrorista na Espanha, mas também marcou um posicionamento popular contra o envio de tropas espanholas ao Iraque (portanto, contra o governo). Está marcada aí a polarização, o confronto entre duas posições diante da ideologia: de um lado, o povo que se coloca no coletivo ("nuestros") e que reivindica a dor e o luto pela perda de civis ("muertos"); de outro, o governo 
espanhol (vuestra") responsabilizado pelas mortes em função de deter o poder de fazer a guerra.

Na manifestação que levou cinquenta mil pessoas às ruas da Espanha, os manifestantes fizeram o percurso pelas ruas da cidade natal de Cervantes em silêncio quase absoluto. Isso nos lembra a passagem do conto Sorôco, sua mãe, sua filha, de Guimarães Rosa (1977), em que o protagonista Sorôco, ao deixar a mãe e a filha no trem que as conduziria ao hospício de Barbacena, volta para casa com a companhia das pessoas da cidadezinha, as quais entoavam com ele o canto alto e desafinado de suas parentas em sinal de solidariedade. O canto toma conta de todos, como um grito em uma manifestação. $O$ canto contagia, se torna um grito de guerra, de um conflito dentro do próprio Sorôco - o seu canto sensibiliza, se torna uma voz comum aos habitantes da cidade. O canto, aparentemente tosco e débil, se coloca na boca de cada um, formando um coro, uma massa que se manifesta com suas contradições e múltiplos sentidos. Tanto o silêncio na Espanha quanto a cantoria roseana contagiam; o silêncio ou a cantoria de um vai adquirindo grandes proporções, tornando-se uma manifestação de uma coletividade, de um "nós" que se manifesta, que se mostra - e se revela.

Importante lembrar que os protestos tiveram uma consequência quase imediata, que foi a mudança do governo espanhol, bem como a repercussão mundial, não somente das manifestações, como também das eleições do país.

Nossa tentativa, neste estudo, foi a de descortinar um pouco do universo que envolve o slogan analisado no que se refere às orientações da $A D$ de linha francesa. Um exercício que não possui um fim. E talvez seja esse o grande fascínio que a AD levanta: o da incompletude; uma incompletude que, por vezes, incomoda, por vezes, se assenta, mas principalmente movimenta. Movimenta o homem em torno do próprio homem e de sua linguagem, sua expressão no mundo, suas significações. Há muito trabalho pela frente, e isso é o mais instigante.

O trabalho não se esgota por aqui. Muitos outros sentidos, com certeza, vão e podem emergir. Cada olhar lançado remete a um novo olhar, e é nesse jogo dialético e dinâmico, nesse constante posicionamento diante dos fatos, na tensão entre o dito e o não dito, entre a paráfrase e a polissemia que $o$ analista do discurso obtém a substância do seu trabalho.

$\mathrm{O}$ analista, desconstruindo a evidência, procura mostrar como um objeto simbólico produz seus sentidos. A contradição e a heterogeneidade intersticial entre a linguagem e as coisas do mundo, próprias da ideologia, permitem que se produza um imaginário cuja interpretação particular aparece 
como a interpretação necessária, devido à atribuição de sentidos fixos em determinadas condições de produção. "Nuestros muertos, vuestra guerra" é, assim, um grito em meio à manifestação. Um grito que pede mais grito, um grito que pede mais silêncio, um grito que não silencia, que não se cala, um grito que significa. Um grito que corta, um grito que cicatriza, um grito que desafia. Agora, façamos novamente silêncio. Ao menos, um minuto.

OUR DEAD, YOUR WAR: DISCOURSE AND THE SILENCING OF SPEECH DURING THE 2004 TERRORIST ATTACKS IN SPAIN

ABSTRACT: Based on French Discourse Analysis, this article sets out to investigate popular discourse about the 2004 terrorist attacks in Madrid, Spain. An analysis of the slogan "Nuestros muertos, vuestra guerra" (our dead, your war) on some demonstration banners of the time, shows that there is no one single meaning for it. This fact highlights the need to look at the context in which the slogan was written and also at the history of production of meaning, which does not just refer to the attacks of 2004, but also to other historical events in the country (separatism and conflict groups) and the global context, such as the 2001 AI Qaeda attacks on USA.

KEYWORDS: Discourse analysis. Silencing. Interdiscourse. Terrorism. Spain.

NUESTROS MUERTOS, VUESTRA GUERRA: EL DISCURSO Y EL SILENCIAMIENTO DEL HABLAR EN LOS ATENTADOS TERRORISTAS EN ESPAÑA EN 2004

Resumen: Usando como base el análisis del discurso de matriz francesa (AD), este artículo tiene como objetivo investigar los discursos populares acerca de los atentados terroristas ocurridos en Madrid, España, en el año del 2004. El análisis del enunciado "Nuestros muertos, vuestra guerra", escrita en algunas fajas en las manifestaciones de la época, reveló que no hay un sentido único para la frase, mostrando la necesidad de que miremos para el contexto del enunciado y para la historia de producción de los sentidos, que no se remite apenas a los atentados de 2004, sino a otros eventos históricos del país (separatismo y grupos de conflicto) y también del contexto mundial, como los atentados de la AI Qaeda a los EUA en 2001.

Palabras Claves: Análisis del discurso. Silenciamiento. Interdiscurso. Terrorismo. España. 


\section{NOTAS}

1. Reboul define o slogan da seguinte maneira: "Chamo slogan uma fórmula concisa e marcante, facilmente repetível, polêmica e frequentemente anônima, destinada a fazer agir as massas tanto pelo seu estilo quanto pelo elemento de autojustificação, passional ou racional que ele comporta; como o poder de incitação do slogan excede sempre seu sentido explícito, o termo é mais ou menos pejorativo". (1975, p. 39).

2. Fazemos aqui uma distinção entre interpretação linguageira, que é aquela feita sob o efeito do esquecimento $n^{\circ} 1$, e interpretação do analista, que se realiza por meio da aplicação de um referencial teórico-metodológico.

\section{REFERÊNCIAS}

ASSIS, M. Dom Casmurro. Série Bom Livro. São Paulo: Ática, 2000.

BAKHTIN, M. Marxismo e filosofia da linguagem. 9. ed.Trad. Michel Lahud e Yara Frateschi Vieira. São Paulo: Hucitec, 1999.

COURTINE, J. J. O chapéu de Clémentis: observações sobre a memória e o esquecimento na enunciação do discurso político. In: INDURSKY, F.; FERREIRA, M. C. L. (Org.). Os múltiplos territórios da Análise do Discurso. Porto Alegre: Sagra Luzzatto, 1999. p. 56-79.

GADET, F.; PÊCHEUX, M. A língua inatingível. Trad. Bethania Mariani. Campinas: Pontes, 2004.

NORA, P. Les lieux de mémoire (Vol. I, La République). Paris: Gallimard, 1984.

NORA, P. Entre a memória e a história: a problemática dos lugares. Projeto História, $\mathrm{n}$. 10, p. 7-28, 1993.

ORLANDI, E. P. As formas do silêncio no movimento dos sentidos. Campinas: Editora da Unicamp, 1995.

ORLANDI, E. P. Análise de Discurso: princípios e procedimentos. Campinas: Pontes, 2001. PÊCHEUX, M. Semântica e discurso: uma crítica à afirmação do óbvio. Campinas: Editora da Unicamp, 1969.

PÊCHEUX, M.; FUCHS, C. A propósito da análise automática do discurso: atualização e perspectivas. In: GADET, F.; HAK, T. (Org.), Por uma análise automática do discurso: uma introdução à obra de Michel Pêcheux. 2. ed. Campinas: Editora da Unicamp, 1993. p. 47-65.

REBOUL, O. O slogan. São Paulo: Cultrix, 1975.

ROSA, J. G. Primeiras estórias. Rio de Janeiro: José Olympio, 1977.

TFOUNI, L. V. Adultos não alfabetizados: o avesso do avesso. Campinas: Pontes Editores, 1988.

WHITMAN, W. Leaves of grass (Folhas de relva). Trad. Rodrigo Garcia Lopes. São Paulo: Iluminuras, 2008. Original publicado em 1855. 
FÁBIO SCORSOLINI-COMIN é professor adjunto do Departamento de Psicologia do Instituto de Educação, Letras, Artes, Ciências Humanas e Sociais da Universidade Federal do Triângulo Mineiro (IELACHS-UFTM); psicólogo (Bacharelado, Licenciatura e Formação de Psicólogo) pela Faculdade de Filosofia, Ciências e Letras de Ribeirão Preto da Universidade de São Paulo (FFCLRP-USP), mestre e doutor em Psicologia pela Universidade de São Paulo (USP), na linha de Subjetividade: Família e Educação. Realizou doutorado sanduíche junto à Faculdade de Psicologia e de Ciências da Educação da Universidade do Porto (Portugal).

E-mail: scorsolini_usp@yahoo.com.br

LEDA VERDIANI TFOUNI é professora titular da Faculdade de Filosofia, Ciências e Letras de Ribeirão Preto da Universidade de São Paulo; líder do grupo AD-Interfaces $(C N P q)$.

E-mail: Ivtfouni@usp.br

ANGELITA ZAMBERLAN NEDEL é psicóloga pela Universidade de São Paulo (USP); psicóloga da Prefeitura Municipal de lçara (SC). E-mail: angelmensagem@yahoo.com.br 